\title{
Correction to: Under-three Year Olds in Policy and Practice
}

\author{
E. Jayne White and Carmen Dalli
}

\section{Correction to:}

\section{E. Jayne White, C. Dalli (eds.), Under-three Year Olds in Policy and Practice, Policy and Pedagogy with Under-three Year Olds: Cross-disciplinary Insights and Innovations, https://doi.org/10.1007/978-981-10-2275-3}

The original version of the book has been published as an Unnumbered Volume under the series Policy and Pedagogy with Under-three Year Olds: Crossdisciplinary Insights and Innovations. The series has been changed to a numbered series now and volume number has been included. The volume number has been updated in the Series Page as follows:

\section{Policy and Pedagogy with Under-three Year Olds: Cross-disciplinary Insights and Innovations}

Volume 1 